\title{
Melhoramento florestal: ênfase na aplicação da biotecnologia
}

\author{
Forestry improvement: emphasis on biotechnology application
}

\author{
Diego Pascoal Golle ${ }^{\mathrm{I}, \mathrm{II}}$ Lia Rejane Silveira Reiniger ${ }^{\mathrm{II}}$ Aline Ritter Curti ${ }^{\mathrm{II}}$ \\ Caroline Borges BevilacquaII
}

\section{-REVISÃO BIBLIOGRÁFICA-}

\section{RESUMO}

As espécies florestais possuem grande importância econômica, pois oferecem diversos produtos fundamentais para a sociedade. Técnicas de melhoramento podem aumentar a produtividade das florestas plantadas, oferecer características desejadas à indústria e reduzir impactos ambientais. No entanto, a baixa variabilidade existente em espécies florestais de crescimento rápido, o longo período para os ciclos reprodutivos e as dificuldades encontradas para a realização de cruzamentos controlados podem inviabilizar tais procedimentos. O objetivo deste trabalho foi realizar uma revisão sobre a contribuição do Melhoramento Genético em espécies perenes, relatando técnicas convencionais e dando especial ênfase à biotecnologia. A cultura de tecidos, a utilização de marcadores moleculares e a transformação genética oferecem soluções únicas para o melhoramento florestal. As principais características que vêm sendo melhoradas estão ligadas à produção de biomassa, alteração na composição de lignina, resistência a pragas, tolerância a herbicidas, machoesterilidade e fitorremediação. Contribuições significativas para a indústria e o ambiente têm sido alcançadas por meio dessas técnicas.

Palavras-chave: cultura de tecidos, marcadores moleculares, transformação genética.

\section{ABSTRACT}

Forest species have great economic importance due to the wide range of important products offered to society. Techniques improvement can increase the productivity of

\begin{abstract}
planted forests, providing the desired characteristics to industry, as well as, reducing environmental impacts. However, the low variability existing in fast-growing species, the long reproductive cycles period and the difficulties encountered when conducting controlled crossings may prevent such procedures. The aim of this research was to carry out a review on the contribution of genetic improvement in perennial species. Conventional techniques with special emphasis on biotechnology were reported. The tissue culture, the use of molecular markers and genetic transformation offer unique solutions to forestry improvement. The major features that have been improved are linked to production of biomass, changes in the composition of lignin, resistance to pests, tolerance to herbicides, male-sterility and phytoremediation. Significant contributions to industry and environment have been achieved through these techniques.
\end{abstract}

Key words: tissue culture, molecular markers, genetic transformation.

\section{INTRODUÇÃO}

O setor florestal possui importância salutar para a economia do Brasil, tendo participação de 3,5\% no PIB brasileiro, equivalente a US \$ 37,3 bilhões. São gerados 4,33 milhões de empregos ligados às florestas plantadas, e 2,58 milhões de empregos ligados a florestas nativas (SBS, 2007). Existem relatos acerca de uma crise na demanda de madeira no Brasil, com vistas a agravar-

'Programa de Pós-graduação em Engenharia Florestal, Centro de Ciências Rurais (CCR), Universidade Federal de Santa Maria (UFSM), Santa Maria, RS, Brasil.

"Departamento de Fitotecnia, UFSM, 97105-900, Santa Maria, RS, Brasil. E-mail: diegolle@yahoo.com.br.*Autor para correspondência. 
se, levando pesquisadores e demais profissionais da área a pensar em estratégias para aumentar a intensidade da produção florestal (TUOTO, 2003). Nesse sentido, o IPEF (2002) cita como prioridades para a silvicultura o desenvolvimento de clones e plantas melhoradas para disponibilização no mercado.

O Melhoramento Genético Florestal pode ser considerado como uma ciência relativamente nova, a qual teve seu maior desenvolvimento, mundialmente, a partir de 1950 e, no Brasil, a partir de 1967, com a implantação da lei de incentivos fiscais ao reflorestamento (RESENDE, 1999). O Melhoramento Genético tem contribuído muito para a produção silvícola. O Brasil encontra-se entre os 10 maiores países em florestas plantadas do mundo, e até 2010 é previsto um acréscimo de $41 \%$ no plantio anual, em relação aos plantios realizados entre 1995 e 2000 (BACHA \& BARROS, 2004).

Apesar disso, no melhoramento de essências florestais por meio de técnicas clássicas, há dificuldades de controle nos processos de polinização e fecundação devido à complexidade na análise dos descendentes, além da necessidade de uma grande área para plantio. Tais fatores inibem os programas de melhoramento com espécies perenes. Soma-se a isso o fato de serem necessários muitos anos para que essas plantas atinjam maturidade reprodutiva e fenotípica, bem como a escassez de mapas genéticos que permitam identificar parentais adequados à hibridização (TZFIRA et al., 1998).

A biotecnologia pode ser utilizada para obtenção de ganhos em produtividade e sustentabilidade, conforme já relatavam, no ano de 1997, WATANABE \& RAMAN, considerando essas técnicas como prioridades mundiais frente à excessiva demanda por produtos oriundos de espécies vegetais. Além disso, também consideraram a proteção ambiental como dependente dessas tecnologias para sua manutenção. As técnicas biotecnológicas, como a cultura de tecidos, utilização de marcadores moleculares, transformação genética, dentre outras, uniram-se ao melhoramento convencional, permitindo a obtenção de genótipos com maior produtividade e qualidade (SARTORETTO et al., 2008).

Face ao exposto, objetiva-se, com este trabalho, apresentar uma revisão sobre o melhoramento de espécies florestais, dando particular ênfase à utilização da biotecnologia.

O melhoramento florestal

As espécies perenes possuem aspectos biológicos peculiares, os quais tornam seu melhoramento bastante diferenciado. Fatores como a sobreposição de gerações, o grande período necessário para o ciclo reprodutivo, a reprodução sexuada e assexuada, a expressão de caracteres ao longo de várias idades, dentre outros, dificultam a execução de técnicas clássicas de melhoramento (RESENDE, 2001).

Em espécies florestais, de modo geral, as estratégias básicas de melhoramento podem ser resumidas em seleção de procedências e seleção individual dentro das populações-base, utilizando-se a variabilidade existente naturalmente dentro das populações e entre os indivíduos. Para recombinação do material genético selecionado, bem como para dar continuidade à seleção recorrente, utilizam-se povoamentos conhecidos como áreas de coleta e produção de sementes ou pomares de sementes por mudas clonais. Testes de progênie convencionais são utilizados para a seleção dos indivíduos superiores. Já por via assexuada, o melhoramento é efetuado por meio do enraizamento de propágulos de árvores selecionadas, muitas vezes híbridas, para a implantação de testes clonais e áreas de multiplicação clonal, fundamentais para a silvicultura intensiva clonal (FERREIRA, 1992).

As principais características que o Melhoramento Florestal tem objetivado são referentes ao incremento do crescimento; da produtividade (madeira, fibras, energia renovável); alterações das propriedades químicas da madeira (teor e tipo de lignina e celulose); modificações das propriedades físicas da madeira (ângulo de fibras, espessura de parede); melhoramento visando a resistência à doenças; a tolerância a estresses abióticos (geadas, seca, salinidade); melhoria da capacidade fotossintética; dos caracteres fisiológicos; uso em biorremediação; a produção de compostos farmacêuticos; alterações na arquitetura da árvore (ramos, nós, interceptação de luz), dentre outros (GRATTAPAGLIA, 2008).

Os ganhos genéticos associados aos retornos financeiros oriundos do Melhoramento dependem das características genéticas oriundas das populações que estão sendo utilizadas no programa de melhoramento; os níveis de conhecimento de tais características, a escolha das estratégias, dos objetivos e das tecnologias que serão utilizadas durante o melhoramento, bem como os custos e retornos associados a este; e o valor dos produtos e serviços oferecidos pelas populações melhoradas (BURLEY \& KANOWSKI, 2005).

Melhoramento clássico, propagação vegetativa e cultura de tecidos vegetais

De forma geral, um programa de Melhoramento Genético Florestal parte de uma 
população-base ou experimental, a partir da qual a seleção será implantada em diferentes intensidades. Essa população selecionada servirá para a produção de sementes ou de mudas clonais, além de servir para a recombinação em novos cruzamentos (RESENDE, 1999). Dentro dessa óptica, um dos problemas que ocorrem é o longo período para a obtenção de um ciclo de melhoramento com espécies perenes, a exemplo do que COSTA et al. (2000) relataram sobre o ciclo que vem sendo utilizado em seringueira (Hevea brasiliensis), o qual compreende uma série de etapas que, para se completarem, necessitam de 20 a 25 anos. Mesmo em espécies de crescimento rápido, o tempo necessário ao florescimento é demasiado longo, se comparado às espécies anuais: em eucalipto é de cinco anos, quando as árvores atingem grande altura, tornando a atividade onerosa e com maiores riscos. Para contornar o problema, as empresas vêm utilizando processos de hibridização indoor, em que plantas de eucalipto são cultivadas em vasos e têm seu florescimento estimulado precocemente por meio de técnicas de poda e reguladores de crescimento, como se fossem bonsais. Dessa forma, as árvores atingem, no máximo, dois metros de altura e florescem com, aproximadamente, 12 meses de idade, facilitando a realização dos cruzamentos controlados (IPEF, 2004; GRATTAPAGLIA, 2008).

Cruzamentos entre plantas perenes têm sido utilizados para a obtenção de características tecnológicas da madeira e da polpa, as quais apresentam herdabilidade de média a alta magnitude (DEMUNER \& BERTOLUCCI, 1993). No entanto, para ASSIS (2008), os limites de variabilidade verificados nas espécies tradicionalmente plantadas, no Brasil, tornam-se um empecilho para a obtenção de indivíduos que possam dar saltos quantitativos e qualitativos no desempenho industrial.

Contudo, observam-se vantagens nos cruzamentos como, por exemplo, em experimentos avaliando a produtividade entre Pinus elliottii, Pinus caribae e seus híbridos $\mathrm{F}_{1}$ e $\mathrm{F}_{2}$, durante 15 anos; DIETERS \& BAWNER (2007) verificaram que $\boldsymbol{P}$. caribae e os híbridos $F_{1}$ e $F_{2}$ excederam a produtividade de forma significativa, quando comparados a $\boldsymbol{P}$. elliottii, havendo pequenas diferenças apenas entre $\boldsymbol{P}$. caribae e os híbridos. PAULA et al. (2003) estudaram o controle genético da eficiência de utilização de fósforo em famílias de meios-irmãos de Eucalyptus grandis. Avaliando 18 famílias, os autores concluíram que há baixa variabilidade entre elas, mas relataram que é possível a seleção de algumas famílias mais promissoras com relação à resposta positiva à adubação fosfatada.
Dentre os métodos mais usados para o Melhoramento Florestal, está a seleção de árvores elites e a sua propagação por meio de clonagem. Plantios clonais oferecem vantagens para a produtividade devido aos seus ganhos genéticos que podem ser aditivos por meio de seleção massal e propagação de indivíduos-elite (SUTTON, 2002). São construídos os jardins clonais, ou minijardins clonais, ou ainda, por micropropagação. Antes do plantio, os clones são submetidos a testes clonais, o que consiste em plantálos em diferentes condições no intuito de confirmar a superioridade existente no material genético (ALFENAS et al., 2004).

Os minijardins clonais, os quais utilizam à técnica de miniestaquia, merecem destaque especial, já que apresentam grande contribuição para a produção florestal e, nessa área, o Brasil apresenta-se como destaque mundial. Conforme HIGASHI et al. (2002), os minijardins estão cada vez mais evoluídos, permitindo a redução de área para produção inicial, a redução no tamanho das estacas e o incremento na produção. Para essas finalidades, utilizam-se vasos, caixas de fibra de vidro e canaletões, sendo estes últimos os mais utilizados por grandes empresas para a produção de clones de Eucalyptus. Avaliando o desempenho de clones de Eucalyptus grandis em comparação às matrizes, SANTOS et al. (2006) observaram a existência de relação significativa entre as características utilizadas para a seleção e o desempenho dos clones ao final dos testes, possibilitando a redução do número de material genético a ser avaliado.

Já as técnicas de Cultura de Tecidos vêm sendo utilizadas de diferentes formas para o desenvolvimento de cultivares superiores de plantas. De maneira geral, elas são requeridas em determinada etapa dos programas de melhoramento, oferecendo novas alternativas e, muitas vezes, soluções únicas (FERREIRA et al., 1998). A micropropagação é a técnica mais utilizada da Cultura de Tecidos e, talvez, a de maior impacto. Possui ampla aplicação na multiplicação de plantas lenhosas como árvores-elite, possibilitando a obtenção de clones mais produtivos (GRATTAPAGLIA \& MACHADO, 1998; ALFENAS et al., 2004).

As técnicas de micropropagação permanecem sendo muito utilizadas. Alguns trabalhos recentes, com espécies perenes, podem ser encontrados, a exemplo de: Maytenus canariensis (GUTIÉRRES-NICOLÁS et al., 2008), Salix pseudolasiogyne (PARK et al., 2008), Ulmus minor (CONDE et al., 2008) e Olea europaea (GYVES et al., 2008), todos relatando protocolos eficientes para a propagação in vitro dessas lenhosas e contornando problemas conhecidos, tais como o estado fisiológico dos explantes e a oxidação fenólica. 
A técnica de cultura de tecidos conhecida como embriogênese somática também é amplamente empregada, especialmente para o desenvolvimento de propágulos de coníferas, possibilitando a propagação massal de famílias-elite de árvores. Para SUTTON (2002), a embriogênese oferece potencial para a produção e para o armazenamento de germoplasma de clones, além da propagação de um número ilimitado de plantas. Em café (Coffea arábica L.), foram observados bons resultados com a utilização de tratamentos "pulse" na indução de embriões somáticos, a partir de cultura de calos (PAPANASTASIOU et al., 2008). Esses tratamentos consistem em expor os explantes, por períodos curtos de tempo, a altas concentrações de reguladores de crescimento em meio líquido e depois transferi-los para meio convencional.

Em Pinus taeda, a produção de mudas a partir da embriogênese somática é um processo muito importante, o qual é utilizado e pesquisado intensamente (PULLMAN et al., 2003). Dentre as vantagens dessa técnica, encontra-se o encapsulamento dos embriões em alginato de sódio, formando sementes sintéticas. Em Pinus patula, embriões foram encapsulados e sua recuperação foi testada. Constatou-se que o melhor armazenamento ocorre em temperaturas reduzidas, permitindo longos períodos de conservação e, além disso, houve melhor germinação dos embriões quando encapsulados (MALABADI \& STADEN, 2005).

Muitos trabalhos podem, também, ser viabilizados pela Cultura de Tecidos, como a obtenção de haplóides, o cultivo de ovários e o cultivo de endosperma. Um exemplo citado por THOMAS \& CHATURVEDI (2008) é a produção de triplóides de Populus tremuloides, permitindo a produção de árvores com qualidade superior de polpa. Ao mesmo tempo, a Cultura de Tecidos é fundamental como requisito para a Transformação Genética, já que, nesse processo, somente um pequeno número de célulasalvo recebem e integram de forma estável o DNA exógeno, sendo necessária a recuperação destas por regeneração in vitro para que a transformação obtenha sucesso (PASQUALI \& ZANETTINI, 2007; SARTORETTO et al., 2008).

Utilização de marcadores moleculares no melhoramento florestal

Até a década de 1960 , os marcadores genéticos utilizados em Genética e Melhoramento eram controlados por genes associados a caracteres morfológicos, os quais ocorrem em pequeno número, reduzindo a probabilidade de encontrar associações significativas entre estes. Com o surgimento dos marcadores moleculares, que são características de DNA que diferenciam dois ou mais indivíduos e são herdadas geneticamente, houve um grande avanço nas pesquisas em Genética e Biologia Molecular de plantas. Os distintos tipos de marcadores moleculares diferenciam-se pela tecnologia utilizada para revelar a variabilidade existente no DNA (FERREIRA \& GRATTAPAGLIA, 1998; MILACH, 1998).

A aplicação de tais marcadores no Melhoramento Genético é extremamente ampla. JONES et al. (2008) determinaram o fluxo de pólen de Eucalyptus grandis por meio de análise de paternidade, utilizando marcadores microssatélites. Vários estudos de estrutura genética de populações e fluxo gênico entre espécies florestais também empregam essas técnicas, como em Araucaria angustifolia, em que foram utilizados marcadores isoenzimáticos (SOUZA, 2000), e em Eugenia dysenterica, em que foram usados marcadores microssatélites e RAPD (ZUCCHI, 2002).

Marcadores moleculares RAPD e SCAR, associados ao caráter florescimento precoce em Eucalyptus grandis, o qual é desejável para a rápida indução de alelos em populações, foram isolados, permitindo a rápida identificação dessas características (DOMINGUES et al., 2006). No Melhoramento Genético da Araucaria angustifolia, STEFENON \& NODARI (2003) caracterizaram a diversidade genética existente na espécie por meio de marcadores RAPD e AFLP e consideraram essas técnicas como poderosas ferramentas na aquisição de conhecimentos. Também são conhecidos mapas de ligação em Eucalyptus grandis por meio de marcadores RAPD; desenvolvimento e caracterização de microssatélites em Eucalyptus urophylla com marcadores RAPD e AFLP, dentre outros (GRATTAPAGLIA \& SEDEROFF, 1997; GAIOTTO et al., 1998).

Trabalhos vêm sendo desenvolvidos no intuito de identificar genes ligados à lignificação (ENDT et al., 2000). ANDRADE et al. (2006) estão estudando o proteoma da madeira para futuros estudos de manipulação genética. Conhecimentos das características da madeira são essenciais, especialmente, para a indústria de celulose, já que reduções no teor de lignina diminuem os custos para sua extração e os impactos ambientais desse processo.

As utilizações dos marcadores moleculares em plantas estão ligadas, principalmente, à identificação de genes, à obtenção de conhecimentos acerca da variabilidade genética das plantas, à certificação de pureza genética, à construção de mapas gênicos e ao mapeamento de QTLs (locos de características quantitativas), à predição de ganhos esperados, à seleção assistida, dentre outros (FERREIRA \& 
GRATTAPALGIA, 1998). Para espécies florestais, os QTLs vêm sendo melhorados. No Brasil, o projeto "Genolyptus" merece destaque quanto ao uso de marcadores moleculares para essa finalidade, dentre outras. Nesse projeto, foi implantada, em 2003, uma rede experimental de campo de grandes proporções, permitindo avanços na compreensão da complexa relação entre fenótipos e genótipos em Eucalyptus (GRATTAPAGLIA, 2006).

A seleção assistida por marcadores (SAM) tem despertado grande interesse dos profissionais da área de silvicultura, pois permite a aceleração dos programas em fases iniciais, o que, geralmente, não é possível de se realizar ao serem avaliados caracteres morfológicos (DOMINGUES et al., 2006). Atualmente, além da seleção assistida por marcadores (SAM), tem sido proposta a Seleção Genômica Ampla (GWS), que se fundamenta no uso de marcadores do tipo SNP (polimorfismos de um único nucleotídeo), os quais resultam da alteração de um único par de bases, sendo esta a forma mais abundante de variação do DNA. Os SNPs podem ser usados para cobrir o genoma de um organismo, gerando marcas que estão, no máximo, a $1 \mathrm{cM}$ (centimorgan) umas das outras. (RESENDE et al., 2008).

Transformação genética em espécies florestais Uma ferramenta de grande potencial no Melhoramento Florestal é a Transformação Genética, a qual está fundamentada na transferência de material genético para uma célula- alvo, de tal forma que o DNA é incorporado e expresso no seu genoma. Os principais métodos de transformação são a biobalística e o uso de Agrobacterium tumefaciens, embora existam outras técnicas (BRASILEIRO \& DUSI, 1999).

Dados do ano de 2003 relatam a existência de aproximadamente 252 testes em campo com árvores transgênicas. A maioria dos testes estão sendo realizados com espécies e híbridos de Populus spp., Pinus spp., Junglans spp. e Eucalyptus spp. No Brasil, testes com eucalipto transgênico resistente a herbicidas estão sendo realizados (STUDART-GUIMARÃES et al., (2003). As principais características florestais que poderiam e vem sendo melhoradas por meio da transgenia estão ligadas à: a) silvicultura (taxa de crescimento, eficiência nutricional, forma do fuste, controle de florescimento, tolerância a herbicidas); b) adaptabilidade (tolerância à seca, tolerância ao frio, resistência a fungos, resistência a insetos) e c) qualidade da madeira (densidade da madeira, redução de lignina, extração de lignina, qualidade de fibra) (DI CIERO \& AMARAL, 2002). Destas, algumas serão discutidas na sequência.
Teor e composição de lignina

Embora a lignina seja um composto de suma importância para a planta, é pouco desejada na indústria de polpa e celulose, já que, para a obtenção desses produtos, deve ser, primeiramente, extraída da madeira, por meio da utilização de compostos que, muitas vezes, são tóxicos ao ambiente (DIOUF, 2003). A baixa variabilidade genética existente para essa característica torna a Transformação Genética desejável, mas esse processo deve ocorrer sem comprometer o desenvolvimento normal da árvore (STUDART-GUIMARÃES et al., 2003). Alguns trabalhos vêm tentando isolar enzimas que desempenham papel-chave na síntese de monolignóis, estas são principalmente a O-methyltransferase (OMT), 4-coumarate-CoA ligase (4CL) e cinnamylalcohol dehydrogenase $(C A D)$, sendo esta última considerada como um dos principais alvos para manipulação genética, já que catalisa o passo final da síntese de monolignóis, conforme relata DIOUF (2003).

Em plantas de álamo (Populus tremula $\mathrm{x}$ Populus alba), a atividade do gene $C A D$ tem sido suprimida, tanto por antisenso, quanto por cosupressão (BAUCHER et al., 1996; SARTORETTO et al., 2008). Foram obtidas plantas transgênicas do híbrido Eucalyptus grandis x Eucalyptus urophylla por meio da expressão do antisenso do gene $C A D$, sendo observada a inibição de $58 \%$ da atividade dos genes de lignificação (TOURNIER et al., 2003). LI et al. (2003) utilizaram estratégias de transformação multigênica (cotransformação) para características de lignina e, por meio do aumento de uma unidade na relação siringil/guaiacil, conseguiram dobrar a remoção de lignina no processo industrial.

\section{Resistência a pragas}

Além dos pesticidas serem tóxicos para o homem e poluírem o ambiente, existem dificuldades de aplicação em espécies florestais devido às extensas áreas de cultivo de florestas e à altura das árvores (STUDART GUIMARÃES et al., 2003). Atualmente, vem sendo relatado o uso mais intensivo de organismos geneticamente modificados com os genes Bt (Bacillus thuringiensis), que atuam formando cristais durante a esporulação do bacilo, denominados Cry (Crystal proteins - ICPs), capazes de perfurar o intestino de insetos após sua ingestão (TANG \& NEWTON, 2003). São conhecidas plantas de Populus nigra, expressando o gene Bt, Eucalyptus camaldulensis, expressando o gene cry $3 A$ e Pinus taeda L., expressando os genes cry1Ac e $B t$ (SARTORETTO et al., 2008). 
Plantas tolerantes a herbicidas

Os herbicidas permitem o aumento da produtividade por meio da redução do surgimento de ervas que competem por nutrientes do solo, água e luz. No entanto, seu uso em grande escala e com aplicações frequentes pode ser tóxico para o homem e o ambiente. Assim, o isolamento e a caracterização de genes de tolerância a herbicidas têm grande importância na obtenção de plantas transgênicas (STUDARTGUIMARÃES et al., 2003). Genes como o aroA mutado, quando são expressos, detoxificam os herbicidas aplicados, permitindo que a planta desenvolva-se normalmente (STUDART-GUIMARÃES et al., 2003). Plantas de Populus tremula x Populus alba foram transformadas com o gene crs1-1, conferindo resistência ao herbicida clorosulfan (BRASILEIRO et al., 1992).

Aumento na produção de biomassa

A alta produtividade, associada ao crescimento acentuado do tronco, é uma das características mais requeridas pela indústria madeireira e de celulose (STUDART-GUIMARÃES et al., 2003). Hormônios foram manipulados com grande sucesso em árvores, por meio da superexpressão de um gene essencial na via de biossíntese da giberelina (GA), o qual codifica para GA 20-oxidase. Plantas transgênicas do híbrido Populus trêmula x Populus tremuloides apresentaram maior crescimento em diâmetro e altura, folhas maiores e fibras numerosas e maiores ERIKSSON et al. (2000).

Esterilidade

Para reduzir a transferência de genes entre plantas transformadas e plantas compatíveis, é necessário o controle do florescimento (TANG \& NEWTON, 2003). A esterilidade possui importante papel nesse enfoque, além de melhorar o crescimento vegetativo em árvores, pois a energia destinada à produção de órgãos reprodutivos é, então, direcionada ao crescimento; pode-se usufruir dessa técnica para controlar cruzamentos em espécies alógamas (SARTORETTO et al., 2008).

Colocados sobre promotores específicos da região do tapetum, determinados genes podem codificar a expressão de citotoxinas que inviabilizarão os tecidos florais. Também para a produção de plantas estéreis pode-se utilizar a supressão ou, então, o bloqueio de genes necessários para desenvolver órgãos de reprodução, por meio do silenciamento ou pelo uso da tecnologia conhecida como antisenso (SARTORETTO et al., 2008).
Remoção de poluentes

O uso de plantas para remover poluentes do ambiente ou torná-los inofensivos é conhecido como fitorremediação. RUGH et al. (1998) obtiveram árvores geneticamente modificadas para fitorremediação de mercúrio, em que Liriodendron tulipifera foi transformado com o gene merA, modificado da linhagem BL308 de Escherichia coli, que codifica a mercúrio redutase. Assim, o mercúrio altamente tóxico $(\mathrm{Hg}++)$ é reduzido a sua forma menos tóxica e volátil (Hg) (SARTORETTO et al., 2008).

Alguns riscos potenciais ao ambiente estão relacionados ao uso de árvores geneticamente modificadas, dos quais podem ser destacados: interações químicas com organismos vivos, mudanças na persistência ou invasividade, fuga de genes, redução na eficiência de controle de pragas, efeitos na biodiversidade nativa, dentre outros (DI CIERO \& AMARAL, 2002). Contudo, muitos benefícios ambientais são trazidos com a biotecnologia, como: a) redução de pressão sobre remanescentes florestais nativos e biodiversidade; b) diminuição de áreas contaminadas por meio do plantio de espécies fitorremediadoras; c) menor intensidade no uso de produtos químicos e d) melhor aproveitamento de áreas degradas, com o plantio de espécies resistentes a estresses abióticos (SARTORETTO et al., 2008).

\section{CONCLUSÕES}

O Melhoramento Genético é indispensável para que seja possível obter o aumento necessário em produtividade, no setor florestal, tanto por meio do uso de técnicas clássicas, quanto por intermédio da biotecnologia. A propagação clonal via miniestaquia merece especial destaque frente ao seu amplo uso e aos excelentes resultados obtidos.

Contudo, técnicas como a Cultura de Tecidos, Marcadores Moleculares e Transformação Genética, são cada vez mais importantes, dando suporte aos programas de Melhoramento e, em diversos casos, apresentando-se como condição sine qua non. Podese inferir que tais técnicas passarão, cada vez mais, a integrar as rotinas dos programas de melhoramento, acelerando e gerando resultados de alta confiabilidade.

\section{REFERÊNCIAS}

ALFENAS, A.C. et al. Clonagem e doenças do Eucalipto. Viçosa: Editora UFV, 2004. 442p.

ANDRADE, A. et al. O proteoma da madeira. Biotecnologia, Ciência \& Desenvolvimento, n.36, p.10-17, 2006.

Ciência Rural, v.39, n.5, ago, 2009. 
ASSIS, T.F. Melhoramento para produtividade e qualidade de celulose de fibra curta. 18p. Capturado em 15 de junho de 2008. Online. Disponível na internet em: http:// ww w. celsofoelkel.com.br/artigos/outros/ A r qu i v o \% $20008 \% 20$ E s t ra t \% E $9 \%$ E 9 gias\%20de\%20Melhoramento\%20FIBRA\%@)CURTA.doc.

BACHA, C.J.C.; BARROS, A.L.M. Reflorestamento no Brasil: evolução recente e perspectiva para o futuro. Scientia Florestalis, n.66, p.191-203, 2004.

BAUCHER, M. et al. Red xylem and higher lignin extractability by down-regulation a cinnamyl alcohol dehydrogenase in poplar. Plant Physiology, v.112, p.1479-1490, 1996.

BRASILEIRO, A.C.M. et al. Expression of the mutant Arabdopsis thaliana acetolactate synthase gene confers chlorsulfuron resistance to transgenic poplar plants. Transgenic Research, v.1, p.133-141, 1992. Disponível em: <http://dx.doi.org/10.1007/ BF02528778>. Doi: 10.1007/BF02528778.

BRASILEIRO, A.C.M.; DUSI, D.M.A. Transformação genética de plantas. In: TORRES, A.C. et al. Cultura de tecidos e transformação genética de plantas. Brasília: EmbrapaSPI/Embrapa-CNPH, 1999. p.679-735.

BURLEY, J.; KANOWSKI, P. Breeding strategies for temperate hardwoods. Forestry, v.78, n.2, p.199-208, 2005. Disponível em: <http://dx.doi.org/10.1093/forestry/cpi018>. Doi: 10.1093/forestry/cpi018.

CONDE, P. et al. A protocol for Ulmus minor Mill. Micropropagation and acclimatization. Plant Cell, Tissue and Organ Culture, n.92, p.113-119, 2008. Disponível em: <http://dx.doi.org/10.1007/s11240-007-9310-8>. Doi: 10.1007/s11240-007-9310-8.

COSTA, R.B. et al. Seleção combinada univariada e multivariada aplicada ao melhoramento genético da seringueira. Pesquisa Agropecuária Brasileira, v.35, n.2, p.381-388, 2000. Disponível em: <http://dx.doi.org/10.1590/S0100-204X2000000200017>. Doi: 10.1590/S0100-204X2000000200017.

DEMUNER, B.J.; BERTOLUCCI, F.L.G. Seleção florestal: uma nova abordagem a partir de estimativas de parâmetros genéticos e fenotípicos para características de madeira e polpa de eucalipto. In: CONGRESSO ANUAL DE CELULOSE E PAPEL DA ABTCP, 26., 1993, São Paulo. Anais... São Paulo: ABTCP 1993. p.422-423.

DI CIERO, L.; AMARAL, W. Árvores geneticamente modificadas na silvicultura intensiva. Biotecnologia, Ciência \& Desenvolvimento, n.29, p.92-98, 2002.

DIETERS, M.; BRAWNER, J. Productivity of Pinus elliottii, $\boldsymbol{P}$ caribaea and their F1 and F2 hybrids to 15 years in Queensland, Australia. Annals of Forest Science, n.64, p.691-698, 2007. Disponível em: <http://dx.doi.org/10.1051/forest:2007049>. Doi: 10.1051/forest:2007049.

DIOUF, D. Genetic transformation of forest trees. African Journal Biotechnology, v.2, n.10, p.328-333, 2003.

DOMINGUES, D.S. et al. Identificação de marcador RAPD e SCAR relacionados ao caractere florescimento precoce em Eucalyptus grandis. Ciência Florestal, v.16, n.3, p.251260, 2006.

ENDT, D.V. et al. Genes de lignificação. Biotecnologia, Ciência \& Desenvolvimento, n.15, p.152159, 2000.
ERIKSSON, M.E. et al. Increased gibberellins biosynthesis in transgenic trees promotes growth, biomass production and xylem fiber length. Nature Biotechnology, v. 18, p. 784788, 2000. Disponível em: <http://dx.doi.org/10.1038/77355>. Doi: $10.1038 / 77355$.

FERREIRA, M. Melhoramento e a silvicultura intensiva clonal. Scientia Florestalis, n.45, p.22-30, 1992.

FERREIRA, M.C. et al. Aplicações da cultura de tecidos no melhoramento genético de plantas. In: TORRES, A.C. et al. Cultura de tecidos e transformação genética de plantas. Brasília: Embrapa-SPI/Embrapa-CNPH, 1998. p.21-43

FERREIRA, M.E.; GRATTAPAGLIA, D. Introduccion al uso de marcadores moleculares em el analisis genético. Brasília: Embrapa-Cenargen, 1998. 221p.

GAIOTTO, F.A. et al. Estimation of outcrossing rate in a breeding population of Eucalyptus urophylla with dominant RAPD and AFLP markers. Theoretical and Applied Genetics, n.97, p.816-827, 1998. Disponível em: <http:/ /dx.doi.org/10.1007/s001220050634>. Doi: 10.1007/ s001220050634.

GRATTAPAGLIA, D. Genômica do Eucalyptus: oportunidades e desafios. In: MARIATH, J.E.A.; SANTOS, R.P. (Orgs.). Os avanços da botânica no início do século XXI: morfologia, fisiologia, taxonomia, ecologia e genética. Porto Alegre: Sociedade Botânica do Brasil, 2006. p.150-156.

GRATTAPAGLiA, D. Melhoramento de Eucalyptus: híbridos, clonagem e marcadores moleculares. Palestra. Capturado em 20 de junho de 2008. Online. Disponível na internet em: http:// ww.cenargen.embrapa.br/palestras/ 21102006/21102006_001.pdf.

GRATTAPAGLIA, D.; MACHADO, M.A. Micropropagação. In: TORRES, A.C. et al. Cultura de tecidos e transformação genética de plantas. Brasília: Embrapa-SPI/Embrapa-CNPH, 1998. p.183-260.

GRATTAPAGLIA, D.; SEDEROFF, R. Genetic linkage maps of Eucalyptus grandis and Eucalyptus urophylla using a pseudotestcross: mapping strategy and RAPD markers. Theoretical and Applied Genetics, n.95, p.842-849, 1997.

GUTIÉRREZ-NICOLÁS, F. et al. Seed germination and in vitro propagation of Maytenus canariensis through regeneration of adventitious shoots from axillary and apical buds. Biologia Plantarum, v.52, n.1, p.173-176, 2008. Disponível em: <http:/ /dx.doi.org/10.1007/s10535-008-0038-z>. Doi: 10.1007/ s10535-008-0038-z.

GYVES, E.M. et al. Stimulation of node and lateral shoot formation in micropropagation of olive (Olea europaea L.) by using dikegulak. Plant Cell, Tissue and Organ Culture, n.92, p.233-238, 2008. Disponível em: <http://dx.doi.org/ 10.1007/s11240-007-9314-4>. Doi: 10.1007/s11240-0079314-4.

HIGASHI, E.N. et al. Propagação vegetativa de Eucalyptus: princípios básicos e sua evolução no Brasil. Piracicaba: IPEF, 2002. 21p. (Circular técnica, 194).

IPEF - Pesquisa florestal desenvolve bonsais de eucalipto. Instituto de pesquisas e estudos florestais, Piracicaba, 2004. $12 \mathrm{p}$.

IPEF. Instituto de Pesquisas e Estudos Florestais. Ciência e tecnologia no setor florestal brasileiro: diagnóstico, prioridades e modelo de financiamento - Relatório Final. Piracicaba: Ministério da Ciência e Tecnologia, 2002. 12p. 
JONES, M.E. et al. Pollen flow in Eucalyptus grandis determined by paternity analysis using microsatellite markers. Tree Genetics \& Genomes, n.4, p.37-47, 2008. Disponível em: <http://dx.doi.org/10.1007/s11295-007-0086-0>. Doi: 10.1007/s11295-007-0086-0.

LI, L. et al. Combinatorial modification of multiple lignin traits in trees through multigene cotransformation. PNAS, v.100, p.4939-4944, 2003. Disponível em: <http://dx.doi.org/ 10.1073/pnas.0831166100>. Doi: 10.1073/pnas.0831166100.

MALABADI, R.B.; STADEN, J. Storability and germination of sodium alginate encapsulated somatic embryos derived from the vegetative shoot apices of mature Pinus patula trees. Plant cell, tissue and organ culture, n.82, 2005. p. 259-256. Disponível em: <http://dx.doi.org/10.1007/s11240-005-13138>. Doi: 10.1007/s11240-005-1313-8.

MILACH, S.C.K. Principais tipos de marcadores moleculares e suas características. In: MILACH, S.C.K. (Ed.). Marcadores moleculares em plantas. Porto Alegre: UFRGS, 1998. p.1728.

PAPANASTASIOU, I. et al. Effect of liquid pulses with 6benzyladenine on the induction of somatic embryogenesis from coffe (Coffea arabica L.) callus cultures. Plant cell, tissue and organ culture, n.92, p.215-225, 2008. Disponível em: <http://dx.doi.org/10.1007/s11240-007-9326-0>. Doi: 10.1007/ s11240-007-9326-0.

PARK, S.Y. et al. Micropropagation of Salix pseudolasiogyne from nodal explants. Plant Cell, Tissue and Organ Culture, n.93, p.341-346, 2008. Disponível em: <http://dx.doi.org/ 10.1007/s11240-008-9362-4>. Doi: 10.1007/s11240-0089362-4.

PASQUALI, G.; ZANETTINI, M.H.B. Transgênese florestal. In: BORÉM, A. Biotecnologia florestal. Viçosa: UFV, 2007. p.317-334.

PAULA, R.C. de. et al. Controle genético da eficiência de utilização de fósforo em famílias de meio-irmãos de Eucalyptus grandis em casa de vegetação. Revista Árvore, v.27, n.1, p.25-34, 2003. Disponível em: <http://dx.doi.org/ 10.1590/S0100-67622003000100004>. Doi: 10.1590/ S0100-67622003000100004.

PULLMAN, G.S. et al. Somatic embryogenesis in loblolly pine (Pinus taeda L.) improving culture initiation with abscisic acid and silver nitate. Plant Cell Reports, v.16, p.85-95, 2003. Disponível em: <http://dx.doi.org/10.1007/s00299-003-0673y>. Doi: 10.1007/s00299-003-0673-y.

RESENDE, M.D.V. Melhoramento de espécies perenes. In: NASS, L.L. et al. (Eds.). Recursos genéticos e melhoramento - plantas. Rondonópolis, MT: Fundação MT, 2001. p.357-421.

RESENDE, M.D.V. Melhoramento de essências florestais. In BORÉM, A. (Ed.). Melhoramento de espécies cultivadas. Viçosa: UFV, 1999. p.589-647.

RESENDE, M.D.V. et al. Seleção genômica ampla (GWS) e maximização da eficiência do melhoramento genético. Pesquisa florestal brasileira, n.56, no prelo, 2008.

RUGH, C.L. et al. Development of transgenic yellow poplar for mercury phytoremediation. Nature Biotechnology, v.16, p.925-928, 1998
SANTOS, G.A. et al. Desempenho silvicultural de clones de Eucalyptus grandis em relação às árvores matrizes. Revista Árvore, v.30, n.5, p.737-747, 2006. Disponível em: <http:// dx.doi.org/10. 1590/S0100-67622006000500007>. Doi: 10.1590/S0100-67622006000500007.

SARTORETTO, M.L. et al. Transformação genética: estratégias e aplicações para o melhoramento genético de espécies florestais. Ciência Rural, v.38, n.3, p.861-871, 2008. Disponível em: <http://dx.doi.org/10.1590/S0103-84782008000300046>. Doi: 10.1590/S0103-84782008000300046.

SBS - Fatos e números do Brasil Florestal. São Paulo: Sociedade brasileira de silvicultura, 2007. 109p.

SOUZA, V.A. Population genetic studies in Araucaria angustifolia (Bert.) O. Ktze. 2000. 161f. Dissertação (Forest Genetics and Forest Tree Breeding) - Faculty of Forest Sciences and Forest Ecology, Gottingen.

STEFENON, V.M.; NODARI, R.O. Marcadores moleculares no melhoramento genético da araucária. Biotecnologia, Ciência \& Desenvolvimento, n.31, p.95-99, 2003.

STUDART-GUIMARÃES, C. et al. Transformação genética em espécies florestais. Ciência Florestal, v.13, n.1, p.167178, 2003.

SUTTON, B. Commercial delivery of genetic improvement to conifer plantations using somatic embryogenesis. Annals of Forest Science, n.59, p.657-661, 2002. Disponível em: <http://dx.doi.org/10.1051/forest:2002052>. Doi:10.1051/ forest:2002052

TANG, W.; NEWTON, R.J. Genetic transformation of conifers and it applications in forest biotechnology. Plant Cell Report, v.22, p.1-15, 2003. Disponível em: <http://dx.doi.org/ 2010.1007/s00299-003-0670-1>. Doi: 10.1007/s00299-0030670-1.

THOMAS, T.D.; CHATURVEDI, R. Endosperm culture: novel method for triploid plant production. Plant Cell, Tissue and Organ Culture, n.93, p.1-14, 2008. Disponível em: <http://dx.doi.org/10.1007/s11240-008-9336-6>. Doi: 10.1007/s11240-008-9336-6.

TOURNIER, V. et al. An efficient procedure to stably introduce genes into a economically important pulp tree (Eucalyptus grandis x E. urophylla). Transgenic Research, v.12, n.4, p.403-411, 2003. Disponível em: <http://dx.doi.org/10.1023/ A:1024217910354>. Doi: 10.1023/A:1024217910354.

TUOTO, M. Entrevista. 2 de abril de 2003. Capturado em 10 de junho de 2005. Online. Disponível na internet em: http:// www.celuloseonline.com.br.

TZFIRA, T. et al. Forest-tree biotecnology: genetic transformation and its application to future forests. Trends in Biotechnology, v.16, p.439-446, 1998. Disponível em: <http:/ /dx.doi.org/10.1016/S0167-7799(98)01223-2>. Doi: 10.1016/ S0167-7799(98)01223-2.

ZUCCHI, M.I. Análise da estrutura genética de Eugenia dysenterica DC. utilizando marcadores RAPD e SSR. 2002. 130f. Tese (Doutorado em Agronomia - Genética e Melhoramento de Plantas) - Programa de Pós-graduação em Agronomia, Escola Superior de Agricultura Luiz de Queiroz, ESALQ/USP. 